\title{
Measurement of reaction time following minor head injury
}

\author{
G MACFLYNN, EA MONTGOMERY, GW FENTON, W RUTHERFORD* \\ From the Department of Mental Health, Queen's University, and the Accident and Emergency Department, \\ Royal Victoria Hospital, ${ }^{*}$ Belfast, $U K$
}

SUMMARY A four-choice reaction time test was carried out on 45 minor head injury cases, 24 hours after the injury and 6 weeks later. Twenty-eight subjects were re-tested after a six month interval. Reaction time measures were also obtained in a matched, general practice control group. The concussion cases displayed significantly poorer performances than the matched controls in four measures, at day 0 and at 6 weeks. The patients also showed serial improvement in these measures up to six months after the injury, when their scores excelled those of the matched controls.

Gronwall and Wrightson ${ }^{1}$ studied various groups of minor head injuries using the Paced Auditory Serial Addition Test (PASAT), as a measure of the rate of information processing. All the concussion patients showed a reduction of the PASAT score, which correlated with symptoms. The authors postulated that the symptoms were directly caused by this diminution of information processing, such as concentration difficulties resulting in stress with headache, and fatigue. However, other workers have found the PASAT to be difficult, tedious for the subject, and unreliable.

After cerebral concussion, patients may also demonstrate a slowing of reaction time which is commonly assumed to reflect a diminution of central information processing. Both simple and choice reaction time measures have been used. Some workers have found the choice reaction time to be more specific. ${ }^{2-4}$ In addition, Miller ${ }^{5}$ demonstrated that increasing complexity correlated with increasing sensitivity to cerebral damage. Other workers ${ }^{6-8}$ reported that the simple reaction time test is as sensitive as the more complex choice reaction time procedure. The conflicting results may be because of the heterogenicity of the subjects in relation to the severity and nature of the lesion, and because of the differing time intervals between the brain insult and

Address for reprint requests: Professor GW Fenton, Department of Psychiatry, University of Dundee, Ninewells Hospital and Medical School, Dundee, DD1 9SY, UK.

Received 20 September 1983 and in revised form 29 February 1984. Accepted 10 March 1984 the required measurement. Most of the studies of head injuries have involved severe trauma. The present study examines the serial change in continuous visual four-choice reaction time during a six month period folowing minor head injury.

\section{Method}

Subjects: Forty-five cases of minor closed head injuries, admitted to a local Accident and Emergency Department, were obtained in the age range of $16-55$ years. The post traumatic amnesia was less than 24 hours in length in all patients. Those suffering from alcohol intoxication or any other complicating illnesses were excluded. The sample consisted of 28 males and 17 females. The mean age was $30.9 \pm 15.9$ years-males $27.7 \pm$ 14.04 years; females $36 \cdot 1 \pm 17 \cdot 9$ years.

Control group A control group of general practice patients was observed; these were collected from the same general practice as that of the index case, by inspection of the general practitioner's case records. Each control was matched with the appropriate head-injured patient for age, sex, marital, social and intellectual status. No one with a history of head injury or any other intra-cerebral event was included in the control group.

Assessments Within 24 hours of admission, the four-choice reaction time test was carried out on the patient group, as part of a large battery of cognitive tests. A number of clinical assessments were carried out on admission, within 48 hours of the injury and 6 weeks later and recorded on forms 1,2 and $3 .^{9}$ Form 1, a questionnaire about details of injury, 326 
alcohol and neurological status, was completed by the casualty medical staff, on admission. Form 2, also completed by the casualty medical staff, recorded the assessment of retrograde and post traumatic amnesia, previous history of concussion, and the presence of relevant signs and symptoms. The symptoms were rated as either present or absent. No attempt was made to grade the intensity of individual symptoms. Their subjective nature makes ratings of severity unreliable and of dubious validity. The only measure of severity available for each patient was the total number of symptoms complained of. The symptoms rated on form 2 are listed in table 1 . Form 2 was completed not later than 48 hours after the accident.

After an interval of 6 weeks, a physical examination was repeated by the casualty staff. Form 3 was also completed (see table 1). This was devoted entirely to symptoms. These were again rated as present or absent, no grading of intensity being attempted. In addition we classified each symptom, recorded on form 3, as "organic" or "psychological" in type. The four-choice reaction time and other cognitive measures were also repeated at this interview. Other assessments of mental state and psychosocial adjustment were carried out on the patients. These data are being currently analysed and will be reported later.

From the original sample of 45 cases, it was possible to follow up 28 patients at 6 months after the head injury. A further four-choice reaction time was obtained, and a second Form 3 was completed.

Apparatus A small, battery powered fully portable device, developed by Wilkinson and Houghton ${ }^{10}$ was used to record the four-choice reaction time. This consists of a cassette tape recorder adapted to contain the display and response apparatus (fig 1), to generate a programme of stimuli and record the responses auditorally. The display consists of four

Table 1

\begin{tabular}{|c|c|}
\hline $\begin{array}{l}\text { Symptoms at day } 0 \text { (Form } 2, R u \\
\text { Headache } \\
\text { Vomiting } \\
\text { Nausea } \\
\text { Drowsiness } \\
\text { Vertigo }\end{array}$ & $\begin{array}{l}\left.\text { erford et } a l^{9}\right) \\
\text { Diplopia } \\
\text { Convulsion } \\
\text { Fatigue } \\
\text { Other from Concussion }\end{array}$ \\
\hline $\begin{array}{l}\text { Symptoms at } 6 \text { weeks and } 6 \text { mon } \\
\text { Organic } \\
\text { Headache } \\
\text { Loss of concentration } \\
\text { Loss of Memory } \\
\text { Dizziness } \\
\text { Diplopia } \\
\text { Other visual difficulties } \\
\text { Hearing Difficulties } \\
\text { Anosmia } \\
\text { Epilepsy } \\
\text { Increased Sensitivity to Alcohol }\end{array}$ & $\begin{array}{l}\left.\text { is, (Form 3, Rutherford et al } l^{9}\right) \\
\text { Psychological } \\
\text { Irritability } \\
\text { Anxiety } \\
\text { Depression } \\
\text { Insomnia } \\
\text { Fatigue }\end{array}$ \\
\hline
\end{tabular}

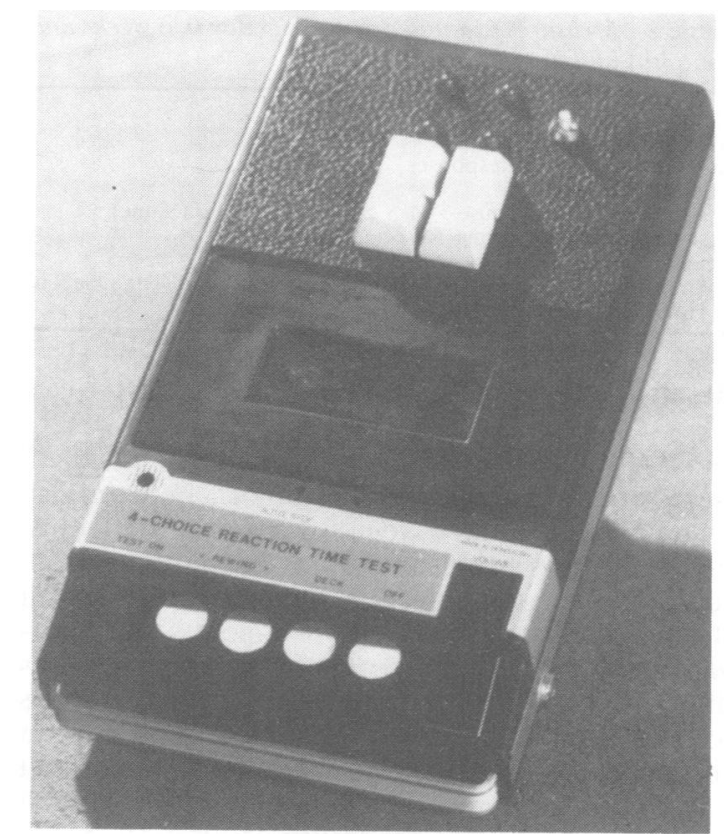

Fig 1 Four-choice reaction time recorder (Wilkinston and Houghton, ${ }^{10}$ )

lights (light emitting diodes or LEDs) mounted in the form of a square; close to these, are mounted four push buttons correspondingly arranged to form a square. The recording sequence commences with one of the lights coming on; the subject starts the test by pressing the button which corresponds geometrically to the light which is on. The light is extinguished and, after 120 milliseconds, either the same light or one of the other lights comes on in random order. The subject responds appropriately and in so doing, brings on the same, or another light, in random sequence. $\mathrm{He}$ is asked to continue to press the button appropriate to the lighted diode, as rapidly and accurately as possible, for a required period of time. In this study, the test period was 10 minutes in duration. When the correct button is pressed, a $2 \mathrm{kHz}$ tone is recorded on tape; a $4 \mathrm{kHz}$ tone records an error. The tapes are replayed through a decoding device, the original sequence of responses being reproduced auditorally in real time. Simultaneous output pulses are generated by the decoder to indicate the correct and incorrect responses. These provide input to a PDP 11/40 computer, which analyses the reaction time according to the parameters listed in table 2 .

Statistical analysis consisted of $t$ testing and the Wilcoxon matched pairs signed rank test. As results were consistently similar with both methods, $t$ test results alone are presented in this paper. 
Table 2 Measures examined in cases at day 0, 6 weeks and 6 months and in controls

Mean Reaction Time all

Number of Total Responses

Number of Correct Responses

Number of Errors

Number of Pauses (Pause $=1.5 \times$ Mean Reaction Time)

Reaction Time of Correct Responses

Reaction Time of Errors

Mean Reaction Time First Half-Mean Reaction Time Second Half Coefficient of Variability

\section{Results}

Serial Change in cases: All the measures in table 2 were serially examined in the subjects between day 0 and 6 weeks and between 6 weeks and 6 months. Figure 2 shows significant improvement of the mean reaction time at all intervals. Other measures which showed significant serial improvement at all intervals are shown in table 3 . The remaining measures did not show consistent serial change. There were as follows: number of errors, number of pauses, mean reaction time of errors, mean reaction time of first half of the test-mean reaction time of second half and the coefficient of variability.

Controls versus cases: There was a significant difference between the mean reaction times of cases at day $0($ mean $=973.5 \mathrm{~ms} \pm 392.7)$ and that of the controls $($ mean $=671.4 \mathrm{~ms} \pm 167 \cdot 7)$, the patients

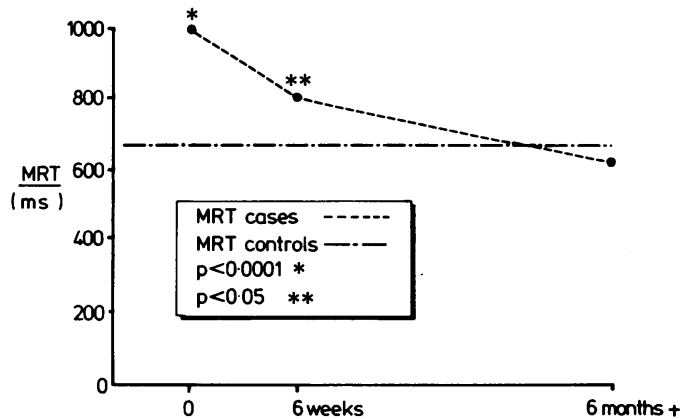

Fig 2 Mean reaction time: Cases $v$ Control and serial changes in cases MRT Cases -..-.-.- MRT Controls --.-·. The cases showed significant serial improvement in the mean reaction time over the six month period. In addition, they were significantly slower at day 0 and at 6 weeks than the controls. At six months, their performance was faster than that of controls.

having the poorer performance (see fig 2 ). This difference was also present at 6 weeks (mean reaction time of cases $=804 \cdot 4 \mathrm{~ms} \pm 326 \cdot 1$ ). The six month measures in mean reaction time all showed the subjects to have improved and, in fact to have slightly faster reaction time, a difference which just reached the $5 \%$ level of significance.

Table 4 shows the values for the subjects and controls for all the four choice measures. The mean

Table 3 Mean values of measures which showed significant serial improvement

\begin{tabular}{|c|c|c|c|}
\hline & Day 0 & 6 weeks & 6 months \\
\hline Mean reaction time all & $999 \cdot 3 \pm 410 \cdot 8$ & $827 \cdot 9 \pm 358 \cdot 2$ & $631 \cdot 0 \pm 154 \cdot 4$ \\
\hline Number of total responses & $565.9 \pm 195.0$ & $664 \cdot 6 \pm 221 \cdot 0$ & $791 \cdot 0 \pm 163.9$ \\
\hline Number of correct responses & $533 \cdot 3 \pm 222 \cdot 0$ & $639 \cdot 6 \pm 221 \cdot 9$ & $771 \cdot 0 \pm 161 \cdot 2$ \\
\hline Mean reaction time of correct responses & $995.4 \pm 413.7$ & $836 \cdot 1 \pm 375 \cdot 5$ & $644 \cdot 0 \pm 183 \cdot 3$ \\
\hline
\end{tabular}

Table 4 Mean values of reaction time measures in controls and cases

\begin{tabular}{|c|c|c|c|c|c|}
\hline \multirow[b]{2}{*}{$\begin{array}{l}\text { Mean reaction time all } \\
\text { Number of total responses } \\
\text { Number of correct responses } \\
\text { Reaction time of correct responses } \\
\text { Coefficient of variability } \\
\text { Number of errors } \\
\text { Number of pauses } \\
\text { Reaction time of errors }\end{array}$} & \multicolumn{2}{|l|}{ Controls } & \multicolumn{3}{|l|}{ Head injury cases } \\
\hline & $\begin{array}{r}671.40 \pm \\
722.47 \pm \\
744.36 \pm \\
754.66 \pm \\
45.5 \pm \\
21.89 \pm \\
51.95 \pm \\
1185.68 \pm\end{array}$ & $\begin{array}{c}256 \cdot 0 \\
194 \cdot 7 \\
193 \cdot 12 \\
401 \cdot 57 \\
17 \cdot 4 \\
23 \cdot 7 \\
17 \cdot 04 \\
1252 \cdot 3\end{array}$ & $\begin{array}{l}\text { Day } 0 \\
* * 999.3 \pm 410.8 \\
* 565.9 \pm 195.0 \\
* * 533.3 \pm 222 \\
+* 995.4 \pm 413.7 \\
\neq 56.2 \pm 24.8 \\
36.98 \pm 68.8 \\
45.97 \pm 17.17 \\
1081.046 \pm 469.9\end{array}$ & $\begin{array}{ll}6 \text { weeks } & \\
\$ 827.9 & \pm 358 \\
\ddagger 664.6 & \pm 221.0 \\
\ddagger 638.6 & \pm 221.9 \\
836.1 & \pm 375.5 \\
50.84 & \pm 21.5 \\
26.90 & \pm 26.9 \\
49.93 & \pm 23.3 \\
829.57 & \pm 522.3\end{array}$ & $\begin{array}{l}6 \text { months } \\
\$ 631.0 \pm 154.4 \\
791.0 \pm 163.9 \\
771.0 \pm 161.2 \\
\$ 644.0 \pm 183.3 \\
46.0 \pm 19.9 \\
19.9 \pm 13.3 \\
54.5 \pm 16.7 \\
885.14 \pm 530.7\end{array}$ \\
\hline
\end{tabular}

$p=0.0001$

$\left.\begin{array}{l}\mathrm{p}=0.0001 \\ \mathrm{p}=0.001 \\ \ddagger \mathrm{p}=0.05\end{array}\right\} 2$ tailed t-test significance levels for comparisons between controls and head injury patients at each interval 
reaction time, number of total responses, number of correct responses, reaction time of correct responses and coefficient of variability showed a significant difference between the control values and the case values at day 0 . At 6 weeks, the reaction time of correct responses and coefficient of variability no longer differed significantly from the control values. There was a trend towards better performance in the cases at 6 months when compared with the controls; this only reached statistical significance in the mean reaction time all measure $(\mathrm{p}=0.049)$ and in reaction time of correct responses $(p=0.05)$.

At no time, did the results for the number of errors, the mean reaction time of errors and the number of pauses differ significantly from those of the controls.

\section{Relation to Symptoms}

At day 0,26 of our cases had three or more symptoms. Their reaction time measures at all intervals were compared with cases who complained of less than three symptoms. Absolute and percentage changes in individual mean reaction times at all intervals were compared in these two groups.

At 6 weeks, 24 cases complained of one or more symptoms. The reaction time measures of this symptomatic group were compared with those who had no symptoms at 6 weeks. Similarly, group comparisons were made between the 14 cases who had organic symptoms and those cases without organic symptoms.

At 6 months, 42 cases completed the symptoms list, or which 20 complained of symptoms. Nineteen cases had at least one organic symptom. The reaction time measures were compared between those with and without symptoms and those with and without organic symptoms. Six monthly choice reaction measures were obtained in 28 cases, of which 15 were symptomatic. The reaction time data of those with and without symptoms were compared. Of these 15 cases, 13 complained of at least one organic symptom. The reaction time measures of these patients were compared with the data obtained from those without organic symptoms.

Furthermore, those cases with headache at day 0 were compared with those who did not complain of headache. Similarly, those with and without vomiting and those with and without drowsiness were compared.

No significant differences in any reaction time measures were found between any of the above groups. In addition, the influence of age was controlled by comparing the differences between the reaction time scores of the matched pairs of cases and controls, for the various groups.

Nineteen cases had a post-traumatic amnesia of less than fifteen minutes, while 24 cases experienced a longer amnesia. No significant differences were found between these groups. Abnormal neurological signs were rare. Hence a meaningful comparison of choice reaction time between those with and without CNS signs was not possible.

EEG and auditory brain stem evoked response recordings were performed within 24 to 48 hours of the trauma and repeated 6 weeks later in 24 out of the 45 patients. Those submitted to EEG study did not differ in age, sex distribution or severity of injury from the rest of the sample, selection of EEG analysis being determined by their availability for recording during the initial short admission period and at follow up. Thirty three percent showed an excess of theta power and almost half had evidence of delayed brain stem conduction time (prolonged $\mathrm{I}-\mathrm{V}$ intervals). These changes were maximal in those patients (12 in all) who had one or more of the following symptoms at the time of the head injury; vomiting, vertigo and diplopia. ${ }^{112}$ No other symptom nor symptom cluster were associated with electrophysiological abnormalities. Hence, it was assumed that vomiting, vertigo and diplopia reflected organic dysfunction, involving especially the brain stem structures. They were termed "core" symptoms. Of the whole group, 22 had one or more core symptoms at day 0 . The latter showed no difference in reaction time measures when compared with the patients without core symptoms.

Only four patients were actively seeking compensation. So no conclusions about the influence of compensation claims on choice reaction time were possible.

\section{Discussion}

There has been much debate over the years as to whether minor head injuries result in any significant cerebral damage and, if present, whether it is demonstrable on psychometric testing. In this study, four measures of a continuous visual four-choice reaction time test were found to improve after minor head injury, from the day after the event until six months later. The performance of the subjects on these same four measures was poorer at day 0 and 6 weeks (except for the reaction time of correct responses which did not differ significantly at 6 weeks), when compared with the matched control group. Six months after the head injury these differences had disappeared, the cases having the better performance. This may be due to a practice effect, despite the long interval between tests. However, such an explanation cannot totally account for the serial improvement between day 0 and 6 weeks and 6 months because of the marked difference between 
the performance of the controls and cases at day 0 and 6 weeks. Such findings suggest causally-linked deficit or deficits, which recover during a period of six months after the brain insult. Gronwall and Wrightson ${ }^{1}$ found recovery in most of their cases after 35 days, with recovery in all after 54 days. The present study demonstrates a more prolonged recovery time.

The same authors found an association between PASAT performance and the presence of symptoms. In this study, no such relationship was apparent. No differences were observed between patients with and without symptoms at any stage. Similar negative findings were made in relation to the presence immediately after the trauma of individual symptoms (headache or nausea) or "core" symptoms (vomiting, vertigo and/or diplopia) of the type that could reflect a more severe degree of cerebral insult at the time of the injury. Severity of symptoms (number per patient) at six weeks and six months did not influence the choice reaction time measures. Neither did the presence of "organic" symptoms at six weeks or six months have any effect. This lack or relationship between the reaction time deficit and symptom occurrence suggests that the two phenomena reflect independent processes. Reaction time performance is a cognitive task requiring continuous information processing and sustained attention and may well be a consequence of a subtle disturbance of cortical function of a global nature.

In contrast, symptom development may result from entirely different mechanisms; organic and psychogenic. Transient focal trauma to the limbic system structures within the middle fossae, as suggested by Trimble,,$^{12}$ could cause psychic symptoms without parallel cognitive impairment. Damage to the cochleovestibular apparatus may account for some of the somatic symptoms such as dizziness and vertigo. Alternatively the persistence of psychic symptoms may be sustained by psychological factors such as genetic predisposition to neurotic behaviour, a vulnerable premorbid personality, the emotional impact of the injury and its repercussions, social and family difficulties. Analysis of our psychosocial data should throw further light on this latter hypothesis.

The length of the post-traumatic amnesia did not mirror four-choice reaction time performance. This may be because of the small range of values; the length of the post-traumatic amnesia was less than 15 minutes in almost one half of the subject group. Also, it is recognised that the length of the posttraumatic amnesia is not a useful measure of cerebral insult in minor head injuries.

One must consider the nature of the deficit or deficits reflected in the findings of this study. Recent studies of reaction time performance have included consideration of the following three dimensions: intrasubject variability, which may reflect disturbances of vigilance, performance decline as an indicator of fatique, and generalised slowing as a result of diminution of central information processing. However, these results must be interpreted cautiously because many of the relevant studies involve a heterogenicity of cerebral pathology. Only a few refer to head injury, usually of the more severe type.

Intrasubject variability has been found to be marked in centrencephalic epilepsy. Bruhn ${ }^{13}$ using a paced continuous reaction time performance test, demonstrated that a slower average reaction time performance in a group of centrencephalic epileptics was primarily due to frequent "lapses" or "blocks" of vigilance or attention. For the fastest reaction time scores, the performance of the epileptics was as rapid as that of the non-epileptic controls, indicating a potential capacity for normal central nervous system processing. Increased variability has also been reported by some workers to occur in brain damaged subjects. ${ }^{7}$ However, Bruhn and Parsons ${ }^{14}$ concluded that general slowing was the major deficit in brain damage and the more variable responses did not indicate actual "lapses" of a normal performance. However, the same authors ${ }^{15}$ when comparing groups of control patients, epileptics and brain damaged subjects, found that the epileptic and brain damaged groups had slower and more variable responses than the controls and did not differ from each other in any measure.

In this study, the head injury cases had a significantly higher intrasubject variability at day 0 when compared with the control group. However, this was not present at 6 weeks. The initial increased variability may reflect vigilance lapses which do not persist and may be the result of an acute pathological process. After 6 weeks, this phenomenon had disappeared, but four other measures of the four choice reaction time were significantly impaired. Therefore it seems that the vigilance lapses are unlikely to be a major feature in the long term recovery from minor head injury.

Some workers have also found fatigue to occur in brain damaged subjects. ${ }^{1617}$ Others did not replicate this. By comparing the mean reaction time in the first half with the second half of the test period, Jeffcoate et $\mathbf{~}^{18}$ have demonstrated that this decline in choice reaction time performance is a useful measure of fatigue. They also found it to occur in alcohol intoxication. In this study there was no difference between performances in the first and second halves of the test. Therefore, fatique can be discounted as a major contributing factor in our results.

Gronwall and Wrightson ${ }^{1}$ remarked that gross 
attention difficulties and fatique are probably more relevant in severe head injuries, the principal dysfunction in minor head injuries being that of slowing of central information processing, with diminution of channel capacity. This is thought to occur in many types of cerebral pathology, especially in cases of head injury. It is interesting that a similar process occurs with ageing. Welford ${ }^{19}$ found that there was a gradual increase in reaction time with the increasing age of subjects. This again can be interpreted as a slowing in central processing. The patients in our sample who had EEG recordings, showed significant slowing of the EEG frequency spectra and prolonged auditory brainstem evoked responses latencies at day 0 as compared with 6 weeks. This is further evidence of central slowing. The reaction time measures which showed serial change in this study can be attributed to this mechanism.

Can clinical use be made of the four-choice reaction time measures? Herbert $e t a^{20}$ concluded that the average reaction time in a four-choice test was a useful measure of the duration and degree of postoperative performance decrement following different anaesthetic techniques. They carried out the four-choice reaction time test in the hospital setting. Gronwall and Wrightson suggested using the PASAT as a predictor of slow recovery from concussion. They proposed that those with poor initial performance should be subject to more intensive rehabilitation. The four-choice reaction time machine is a portable, convenient apparatus, which may be administered in any setting, even in a busy casualty ward. The test period may be as short as 5 minutes, and the procedure is not tedious. Serial changes in performance could therefore be useful as an indicator of underlying dysfunction. Normative data have been collected by Luskutova ${ }^{21}$ in the USSR. Were such a data base available for subjects in this country, the four-choice reaction could be used as a sensitive measure of impaired function after concussion and as a monitor of the recovery progress. Further work, looking at serial changes of performance in both controls and concussed patients, is necessary to explore this possibility.

The authors thank the staff of the Accident and Emergency Department, Royal Victoria Hospital, Belfast, for their help. We also gratefully acknowledge the statistical advice given by Dr Chris Patterson, Department of Medical Computing and Statistics, the Queen's University, Belfast. The fourchoice reaction time analysis program was prepared by Dr GA Armstrong, former Senior Research Officer in the Department of Mental Health, the Queen's University, Belfast. The research was supported by a grant from the Medical Research Coun- cil and part of it was carried out while one of the authors (EAM) was a holder of a Royal Victoria Hospital clinical research fellowship.

\section{References}

${ }^{1}$ Gronwall D, Wrightson P. Delayed recovery of intellectual function after minor head injury. Lancet, 1974;2:605-9.

${ }^{2}$ Van Zomeren AH, Deelman BG. Long-term recovery of visual reaction time after closed head injury. $J$ Neurol Neurosurg Psychiatry, 1978;41:452'-7.

${ }^{3}$ Norrman B, Svahn K. Follow-up study of severe brain injuries. Acta Neurol Scanda, 1961;37:236-64.

${ }^{4}$ Rosvold HE, Mirsky AF, Sarason I, Bransome ED Jr., Beck LH. A continuous performance test of brain damage. J Consult Psychol 1956;20:343-50.

${ }^{5}$ Miller E. Simple and choice reaction time following severe head injury. Cortex, 1976;6:121-7.

- Blackburn HL, Benton AL. Simple and choice reaction time in cerebral disease. Conf Neurol 1970;15:32738.

${ }^{7}$ Benton AL, Blackburn HL. Practice effects in reaction time tasks in brain-injured patients. J Abnorm Social Psychol, 1958;54:109-113.

${ }^{8}$ Klensch H. Die diagnostische Valenz der Reaktionszeitmessung bei verschiedenen zerbralen Erkankungen. Fortschr Neurol Psychiatr, 1973;41:575-81.

9 Rutherford WH, Merrett JD, McDonald JR. Sequalae of concussion caused by minor head injuries. Lancet 1977;1:1-4.

${ }^{10}$ Wilkinson RT, Houghton D. Portable four-choice reaction time test with magnetic tape memory. Behaviour Research Methods and Instrumentation 1975;7:441-6.

"Montgomery A, Fenton GW, McClelland RJ. The postconcussional syndrome-evidence for delayed brainstem conduction time. Lancet 1984;1:1011.

12 Trible MR. Post-traumatic Neurosis. Chichester: Wiley, 1981.

${ }^{13}$ Bruhn P. Disturbance of vigilance in sub-cortical epilepsy. Acta Neurol Scand 1970;46:442-54.

14 Bruhn P, Parsons OA. Continuous reaction time in brain damage. Cortex 1971; 7:278-91.

is Bruhn P, Parsons OA. Reaction time variability in epilepsy and brain-damaged patients Cortex 1977; 13: 373-84.

${ }^{16}$ Goldstein K. After-effects of Brain-injuries in War. New York: Grune and Stratton, 1942.

${ }^{17}$ McDonald RD, Burn SB. Visual vigilance and brain damage-an empirical study. J Neurol Neurosurg Psychiatry 1964;27:206-9.

18 Jeffcoate WJ, Herbert M, Cullen MH, Hastings AG, Walder CP. Prevention of effects of alcohol intoxication by Naxolone. Lancet 1979;ii: 1157-9.

19 Welford AT. On changes of performance with age. Lancet 1962;i:335-9.

${ }^{20}$ Herbert M, Healey TE, Bourke JB, Fletcher IR, Rose JM. Profile of recovery after general anaesthesia. $\mathrm{Br}$ Med J 1983;286: 1539-42.

${ }^{21}$ Luskutova TD. Parameters of the reaction time as criteria of the human brain functional state. Fiziologischeski Zhurnal S.S.R., 1975;61:3-12. 